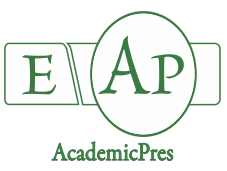

Luo C et al. (2021)

Notulae Botanicae Horti Agrobotanici Cluj-Napoca

Volume 49, Issue 3, Article number 12441

DOI: $10.15835 /$ nbha49312441

Research Article

\title{
Characterization of Colletotrichum siamense causing crown rot of strawberry in Jingzhou, Hubei Province
}

\author{
Chun LUO, Yuyang HU, Bo SHU*
}

Yangtze University, College of Horticulture and Gardening, 1 Nanhuan road, Jingzhou, China; luochunclock@126.com;

598944714@qq.com; bshbest@163.com("correspondingauthor)

\begin{abstract}
Crown rot (Colletotrichum siamense) of strawberry is a severe disease in Jingzhou, Hubei Province, China. Pathogen identification is the basis for disease prevention and resistance breeding. Nearly fifty isolates were achieved from 192 crown rot samples in this study. A number of 21 isolates were characterized as the pathogen of crown rot of strawberry by Koch's postulates, and they were identified as Colletotrichum spp. by conidia morphology observation. The 21 isolates were divided into three groups based on colony morphology, and SCR-7, SCR-11 and SCR-16 belonged to each group were clustered into one group with $C$. siamense isolates by phylogenetic analysis of actin, $\beta$-Tubulin 2 and calmodulin sequences. In addition, the isolates of $C$. siamense SCR-7 showed the strongest pathogenicity of the three which caused highest values of lesion length and leaf temperature, and lowest leaf water content, photosynthetic rate, stomatal conductivity and even transpiration rate values. This study contributes to updating the Colletotrichum species associated with strawberry of China.
\end{abstract}

Keywords: anthracnose; crown rot; Colletotrichum siamense; phylogenetic; pathogenicity

\section{Introduction}

Strawberry (Fragaria $\times$ ananassa Duch.) is an important perennial herbaceous berry in China, which achieved 120 thousand hectares cultivation area and more than 3.060 million tons (National Bureau of Statistics, 2019). Crown rot is a serious disease, which threaded strawberry cultivation worldwide (Noh et al., 2018; Zhang et al., 2020). The pathogen of crown rot is complex, which include Colletotrichum, Phytophthora, Neopetalotiopsis and many other fungi (Noh et al., 2018; Park et al., 2019; Zhang et al., 2020).

The incidence of strawberry crown rot was as high as $45.4 \%$ in 2012 in Hubei Province (Han et al., 2014), and the damage of this disease is becoming more serious in recent years. Crown rot leads to the collapse of the drainage tissue, and the aboveground part wilts, and then quickly withers, and finally the aboveground parts die in summer and autumn with hot and rainy (Xie et al., 2010; Jayawardena et al., 2016). Identifying the pathogen and taking pathogenicity assays are important for control of strawberry crown rot. C. siamense was identified as the pathogen of strawberry crown rot in Wuhan (Han et al., 2014), but the pathogen had not been isolated and identified in Jingzhou City, which is located 200 kilometres away from Wuhan. Whether the pathogen was the same as Wuhan or mixed infection by other pathogens? Whether the pathogenicity of pathogen was different?

Received: 15 Jul 2021. Received in revised form: 02 Aug 2021. Accepted: 09 Aug 2021. Published online: 18 Aug 2021.

From Volume 49, Issue 1, 2021, Notulae Botanicae Horti Agrobotanici Cluj-Napoca journal uses article numbers in place of the traditional method of continuous pagination through the volume. The journal will continue to appear quarterly, as before, with four annual numbers. 
In this study, a combination of morphological and phylogenetic analysis was used to identify the pathogen causing strawberry crown rot. Mycelial growth rate on PDA plate of each isolate, the lesion size on crown of each isolate treatment, the relative water content, photosynthetic rates, stomatal conductivity, transpiration rates, leaf temperature, and intercellular $\mathrm{CO}_{2}$ concentration of leaf with isolate treatment were measured for pathogenicity assays. This study clarified the pathogen types of strawberry crown rot disease in Jingzhou, Hubei Province, China and compared isolate pathogenicity, which would provide a theoretical basis for the disease control and strawberry disease resistance breeding.

\section{Materials and Methods}

\section{Pathogen isolation}

One hundred and ninety-two crown samples were achieved from crown root rot with wilting 'Benihoppe' strawberry seedlings in Jingzhou, Hubei Province, China. The samples of adjacent tissues of rot and health were cut into $0.5 \mathrm{~cm} \times 0.5 \mathrm{~cm}$ pieces and placed into $0.1 \%$ aqueous mercuric chloride for $1 \mathrm{~min}$, and then washed 3 times with sterile water for 1 min each time. The diseased tissues were placed on potato dextrose agar (PDA) plate with $28^{\circ} \mathrm{C}$ under continuous light for 3 days. After that, a small amount of hyphae was picked from the edge of the grown colony to inoculate a new PDA plate for 3 days (Han et al., 2014). Nine healthy and consistent one-year old 'Benihoppe' strawberry seedlings were inoculated for each isolate. The seedlings were cultivated in three pots, and three seedlings in each pot. The seedlings of one pot were taken as one biological replicate, so three biological replicates were used for pathogen identification. The crowns were surface-sterilized with $70 \%$ alcohol for $10 \mathrm{~s}$, and then rinsed three times with sterile water. The crowns were wounded using a sterilized toothpick, a single mycelial plug ( $4 \mathrm{~mm}$ in diameter $)$ of isolates was placed onto the wound, and a plug of sterile PDA medium was placed onto the wound as the controls (Wang et al., 2011). The symptoms of each isolate were observed after 1 week after inoculation, the seedlings which appeared wilting and crown root rot same as previous host were isolated again. At last, fifteen isolates were verified as the pathogen of strawberry in Jingzhou City.

\section{Morphology identification of pathogens}

Fifteen isolates were inoculated on PDA medium and incubated at $28{ }^{\circ} \mathrm{C}$ for 10 days, and then the colony morphology was observed. A small amount of conidia from the pile of conidia on the PDA plate was picked using a sterile toothpick, suspended in sterile water, and then the morphology of the pathogenic fungal conidia was observed via an optical microscope (Leica M125., Germany) and the length and width of 20 conidia were measured. Three types of isolates with different colony morphology were chose from fifteen isolates. Holes were punched from edge of the three isolates colony using a $0.5 \mathrm{~cm}$ hole puncher, and the hyphae blocks were inoculated in the center of the PDA plate. The PDA plate was placed in a constant temperature incubator at $18{ }^{\circ} \mathrm{C}$ for 4 days in the dark, and then colony diameter was measured. The pathogens were characterized as Colletotrichum based on the taxonomic criteria of morphological characteristics (colony characters, conidial and setal morphology and production of a teleomorph) according to that described by Gunnell and Gubler (1992).

\section{Molecular identification of pathogens}

The hyphae of three isolates were quick-frozen with liquid nitrogen, and ground into powder and taken as template for PCR amplification directly. The PCR amplification of actin (ACT), beta-tubulin 2 (TUB2) and calmodulin $(C A L)$ of three isolates were carried out, respectively. The primers and PCR amplification program was following the method of Han et al. (2014). The annealing temperature of PCR amplification of three genes was different. The PCR annealing temperatures were $59^{\circ} \mathrm{C}, 55^{\circ} \mathrm{C}$ and $58^{\circ} \mathrm{C}$ for $C A L, T U B 2$ and $A C T$, respectively (Han et al., 2014). After detection for agarose gel electrophoresis, the PCR products were 
sequenced by Qingke Biotechnology Co., Ltd. using PCR amplification primers corresponding to each gene, after that the sequence were uploaded to the GenBank database (Table 1).

Taking the corresponding gene sequences of $C$. hippeastriand $C$. boninense as the outgroup (Damm et al., 2012), MEGA 4.0 software was used to perform phylogenetic evolution analysis based on the CAL, TUB2, and $A C T$ gene sequences of each strain (Tamura et al., 2007; Liu et al., 2013). The neighbour-joining (NJ) method was used to construct phylogenetic tree, repeat 1,000 times. Bootstrap value of each branch in the NJ phylogenetic tree was calculated.

Table 1. Strains and sequence used in this study

\begin{tabular}{|c|c|c|c|c|}
\hline \multirow{2}{*}{ Species } & \multirow{2}{*}{ Strain } & \multicolumn{3}{|c|}{ GenBank accession number } \\
\hline & & $A C T$ & $T U B 2$ & $C A L$ \\
\hline \multirow{3}{*}{ Uncharacteristic } & SCR-7 & MZ436924 & MZ436927 & MZ436930 \\
\hline & SCR-11 & MZ436925 & MZ436928 & MZ436931 \\
\hline & SCR-16 & MZ436926 & MZ436929 & MZ436932 \\
\hline Colletotrichum aenigma & ICMP18608 & JX009443 & JX010389 & JX009683 \\
\hline C. aeschynomenes & ATCC201874 & JX009483 & JX010392 & JX009721 \\
\hline C. alatae & ICMP17919 & JX009471 & JX010383 & JX009738 \\
\hline C. alienum & ICMP18691 & JX009580 & JX010385 & JX009664 \\
\hline C. aotearoa & ICMP18532 & JX009544 & JX010421 & JX009614 \\
\hline C. asianum & ICMP18696 & JX009576 & JX010384 & JX009723 \\
\hline C. boninense & ICMP10338 & JQ005507 & JQ005593 & JQ005680 \\
\hline C. clidemiae & ICMP18706 & JX009476 & JX010439 & JX009639 \\
\hline C. cordylinicola & ICMP18579 & HM470235 & JX010440 & HM470238 \\
\hline C. fructicola & ICMP18613 & JX009491 & JX010388 & JX009675 \\
\hline C. gloeosporioides & ICMP17821 & JX009531 & JX010445 & JX009731 \\
\hline C. hippeastri & CBS125377 & JQ005753 & JQ005580 & JQ005666 \\
\hline C. horii & ICMP12942 & JX009533 & JX010375 & JX009603 \\
\hline C. kahawae & ICMP18539 & JX009523 & JX010434 & JX009635 \\
\hline C. musae & ICMP17817 & JX009432 & JX010395 & JX009689 \\
\hline C. nupharicola & ICMP17938 & JX009486 & JX010397 & JX009661 \\
\hline C. psidii & ICMP19120 & JX009515 & JX010443 & JX009743 \\
\hline C. queenslandicum & ICMP1778 & JX009447 & JX010414 & JX009691 \\
\hline C. salsolae & ICMP19051 & JX009562 & JX010403 & JX009696 \\
\hline C. theobromicola & ICMP17958 & JX009498 & JX010381 & JX009598 \\
\hline C. $t i$ & ICMP5285 & JX009553 & JX010441 & JX009650 \\
\hline C. tropicale & ICMP18672 & JX009480 & JX010396 & JX009722 \\
\hline C. xanthorrhoeae & ICMP17903 & JX009478 & JX010448 & JX009653 \\
\hline Glomerella cingulata & ICMP18542 & JX009488 & JX010429 & JX009628 \\
\hline \multirow[t]{8}{*}{ C. siamense } & ICMP12567 & JX009541 & JX010387 & JX009697 \\
\hline & ICMP17795 & JX009506 & JX010393 & JX009703 \\
\hline & ICMP18121 & JX009460 & JX010402 & JX009715 \\
\hline & CBS112983 & KC296929 & KC297100 & KC296961 \\
\hline & CBS113199 & KC296930 & KC297090 & KC296962 \\
\hline & Zhd-3 & KF110981 & KF055337 & KF110984 \\
\hline & Zhd-4-1 & KF110982 & KF055338 & KF110985 \\
\hline & Zhd-5 & KF110983 & KF055339 & KF110986 \\
\hline
\end{tabular}

\section{Pathogenicity assays}

The plant materials in a single factor experiment were used for pathogenicity assays. Seventy-two oneyear old healthy and consistent 'Benihoppe' strawberry seedlings, grown in twenty-four pots with three in one 
pot, were divided into four groups equally for inoculation with $C$. siamense SCR-7, SCR-11, SCR-16 and nontoxic medium (control) as previous. Three seedlings grown in each pot were achieved mixed and taken as one biological replicate, thus six biological replicates were used for pathogenicity assays. After 1 week seedlings inoculation of each isolate (inoculated on PDA medium and incubated at $28^{\circ} \mathrm{C}$ for 1 week), the lesion size was measured. Fourth fully expanded top leaf was used for leaf gas exchange including photosynthetic rates ( $\mathrm{Pn})$, stomatal conductivity (gs), transpiration rates $(\mathrm{E})$, leaf temperature, and intercellular $\mathrm{CO}_{2}$ concentration $(\mathrm{Ci})$ was determined using a Li-6400 portable photosynthesis system (Li-Cor Inc., Lincoln, USA) from 9:30 am to 10:30 am following the method of Huang et al. (2020). Relative water content (RWC) of the fourth fully expanded top leaf was estimated with the following formula (Zou et al., 2015) after photosynthetic parameters measurement: RWC $(\%)=(F W-D W) /(S W-D W) \times 100$, where FW stands for fresh weight, DW for dry weigth at $75^{\circ} \mathrm{C}$ for $48 \mathrm{~h}$, and SW for saturated weight after leaf rehydration for $24 \mathrm{~h}$.

\section{Statistical analysis}

All the data were analysed with analysis of variation (SAS, v 8.1, Cary, USA), and significant differences between treatments were compared by Duncan's multiple range tests at $\mathrm{P}=0.05$ level.

\section{Results}

\section{Isolation of fungi}

Fifty isolates were achieved from one hundred and ninety-two crown samples which exhibited typical rots symptoms (Figure 1). Twenty-one isolates were confirmed as pathogen of strawberry crown rot by Koch's postulates. On PDA, the colony colour of twenty-one showed three different types, grey colonies on the front and red wheel in back; white colonies with red rings on the front and yellow wheel in back; grey colonies on the front and black speck in back (Figure 2a; 2b). The conidia morphology of three isolates with different colonial morphologies was nearly the same. Most of the conidia were narrowly obovate, straight or occasionally slightly curved and with obtuse ends (means \pm SE, length $17.12 \pm 0.12 \mu \mathrm{m}$; width $4.05 \pm 0.32 \mu \mathrm{m}$ ) (Figure $2 \mathrm{c}$ ). The pathogens were characteristic as Colletotrichum based on taxonomic criteria of morphological characteristics.

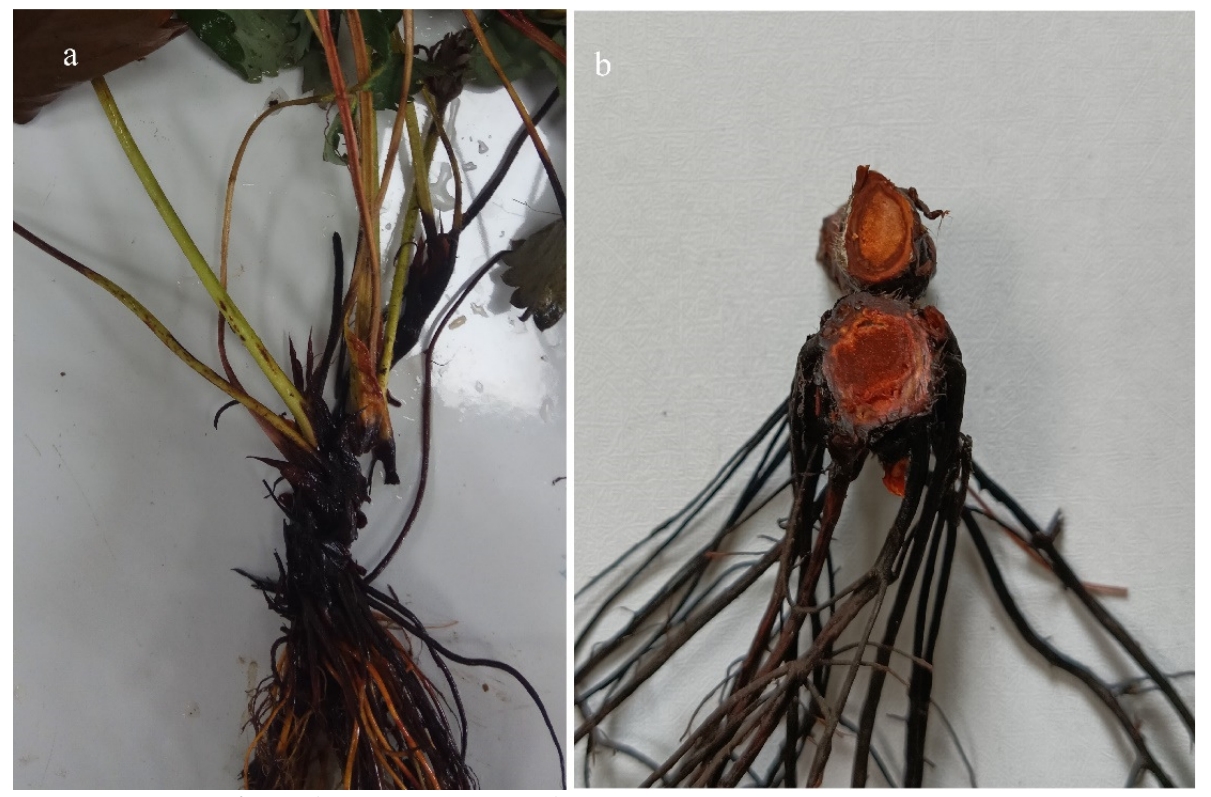

Figure 1. Symptoms of strawberry crown rot and root rot 

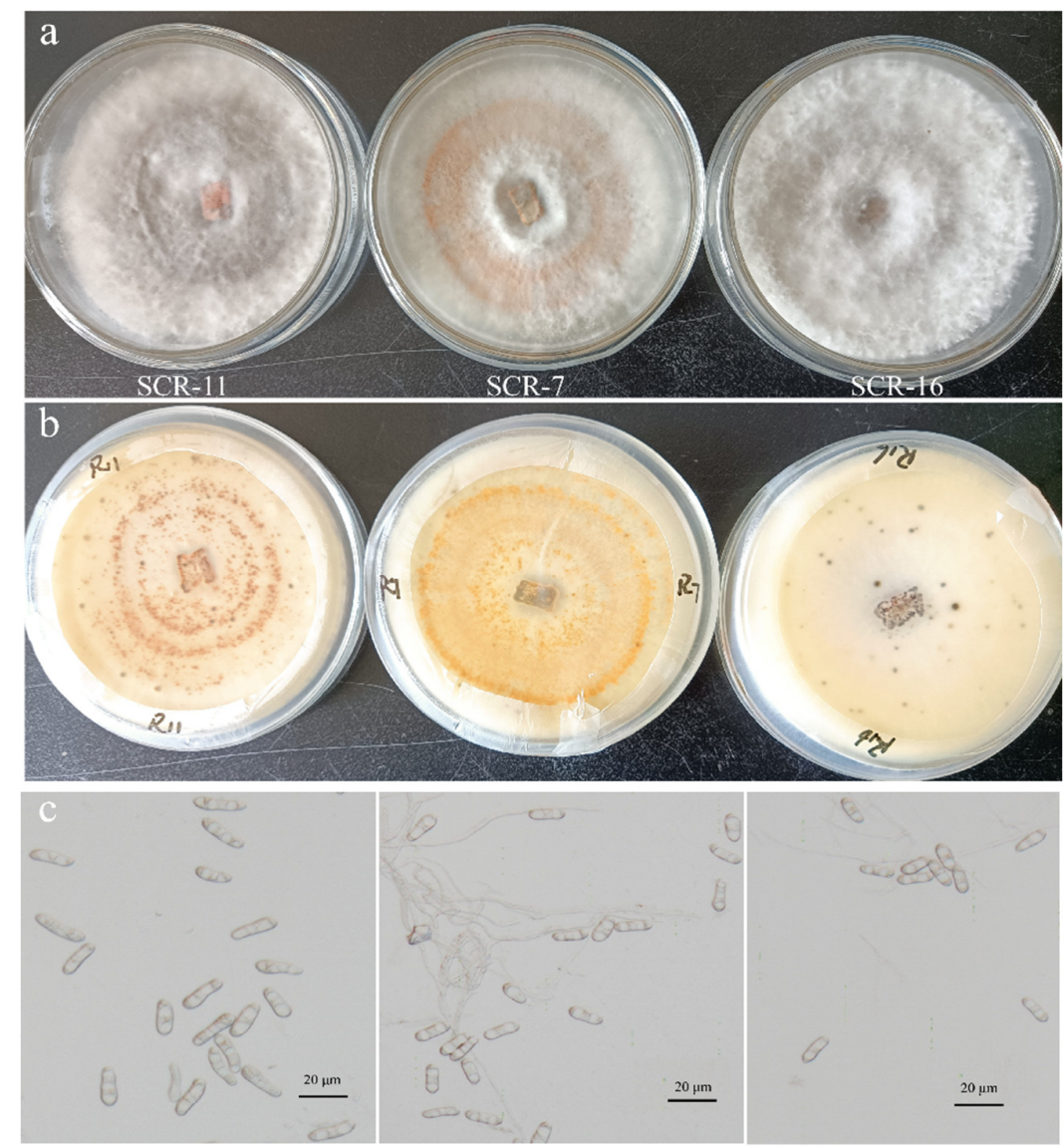

Figure 2. The characteristics of biological morphology

Figure $2 \mathrm{a}$ and $2 \mathrm{~b}$ showed the colony morphology of SCR-7, SCR-11, and SCR-16 on potato dextrose agar after 10 days of incubation in $28^{\circ} \mathrm{C}$ from above and below, respectively; Figure $2 \mathrm{c} \mathrm{showed} \mathrm{conidia} \mathrm{under} \mathrm{optical} \mathrm{microscope.}$

\section{Phylogenetic analysis}

$C A L, A C T$ and TUB2 sequence data were achieved from three isolates with different colonial morphology, respectively. The sequence data of our isolates of Colletotrichum and recent publications on Colletotrichum strains were used for phylogenetic tree construction for pathogen characteristic and phylogenetic analysis. The combined gene alignment of $C A L, A C T$ and $T U B 2$ for three isolates supported those pathogens were $C$. siamense named $C$. siamense strain SCR-11, C. siamense strain SCR-7 and $C$. siamense strain SCR-16. Three groups of $C$. siamense were shown in phylogenetic tree. Our isolates were clustered together in group I, and three isolates were clustered with $C$. siamense strain ICMP:12567 and $C$. siamense strain Zhd-4-1 (Figure 3).

\section{Pathogenicity studies}

The inoculated strawberry seedlings began wilting after $10 \mathrm{~d}$ of inoculation and showed growth retardation. Necrosis was observed in crown of the wilted plants. The longitudinal section of the crown showed red brown. The lesion length ranged 0.6 to $1.2 \mathrm{~cm}$, and the $C$. siamense SCR-7 grew faster significantly than other isolates on 2 weeks after inoculation. However, the lesion width caused by the three isolates showed no difference (Figure 4). 


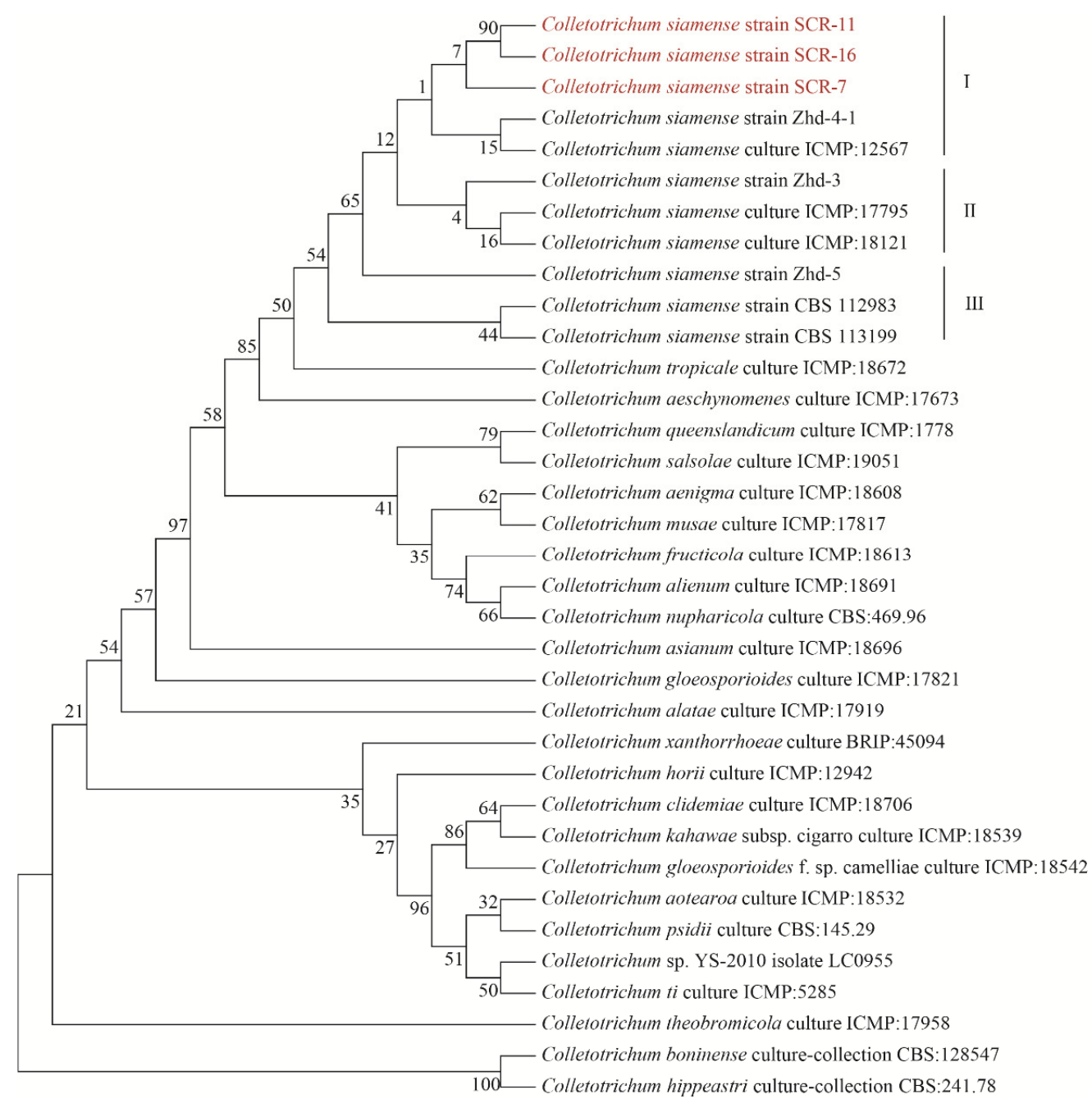

Figure 3. Phylogenetic tree of Colletotrichum gloeosporioides species complex based on the $A C T, C A L$, and $T U B 2$ sequences

As the crown rot caused wilting, leaf water content and temperature were measured for characterizing pathogenicity of the three isolates. The inoculation of three isolates exhibited lower leaf water content than that in control, and $C$. siamense SCR-7 remarkably reduced leaf water content than other isolates. Corresponding to leaf water content, C. siamense SCR-7 inoculation promoted leaf temperature to $35.3{ }^{\circ} \mathrm{C}$ which was significantly higher than other two isolates and control (Figure 5).

Photosynthetic parameters were also determined for analyzing pathogenicity of the three isolates because the crown rot caused wilting. Compared with control, the Pn, E, and gs were all decreased significantly in seedlings inoculated with $C$. siamense. In addition, the seedlings inoculated with $C$. siamense SCR-7 exhibited the lowest $\operatorname{Pn}\left(8.47 \pm 0.24 \mu \mathrm{mol} / \mathrm{m}^{2} / \mathrm{s}\right)$ and gs $\left(53.47 \pm 4.21 \mu \mathrm{mol} / \mathrm{m}^{2} / \mathrm{s}\right)$ value, and the lowest $E$ value was possessed by the seedlings inoculated with $C$. siamense SCR-7 $\left(1.41 \pm 0.14 \mu \mathrm{mol} / \mathrm{m}^{2} / \mathrm{s}\right)$ and $C$. siamense SCR-11 $\left(1.36 \pm 0.11 \mu \mathrm{mol} / \mathrm{m}^{2} / \mathrm{s}\right)$. Compared with control, inoculation with $C$. siamense remarkably increased the Ci values. And the seedlings inoculated with $C$. siamense SCR-7 and $C$. siamense SCR-11 showed the highest $C i$ value of the four treatments, which were $166.25 \pm 5.71 \mu \mathrm{mol} / \mathrm{m}^{2} / \mathrm{s}$ and $159.75 \pm 4.58 \mu \mathrm{mol} / \mathrm{m}^{2} / \mathrm{s}$, respectively (Figure 6). 

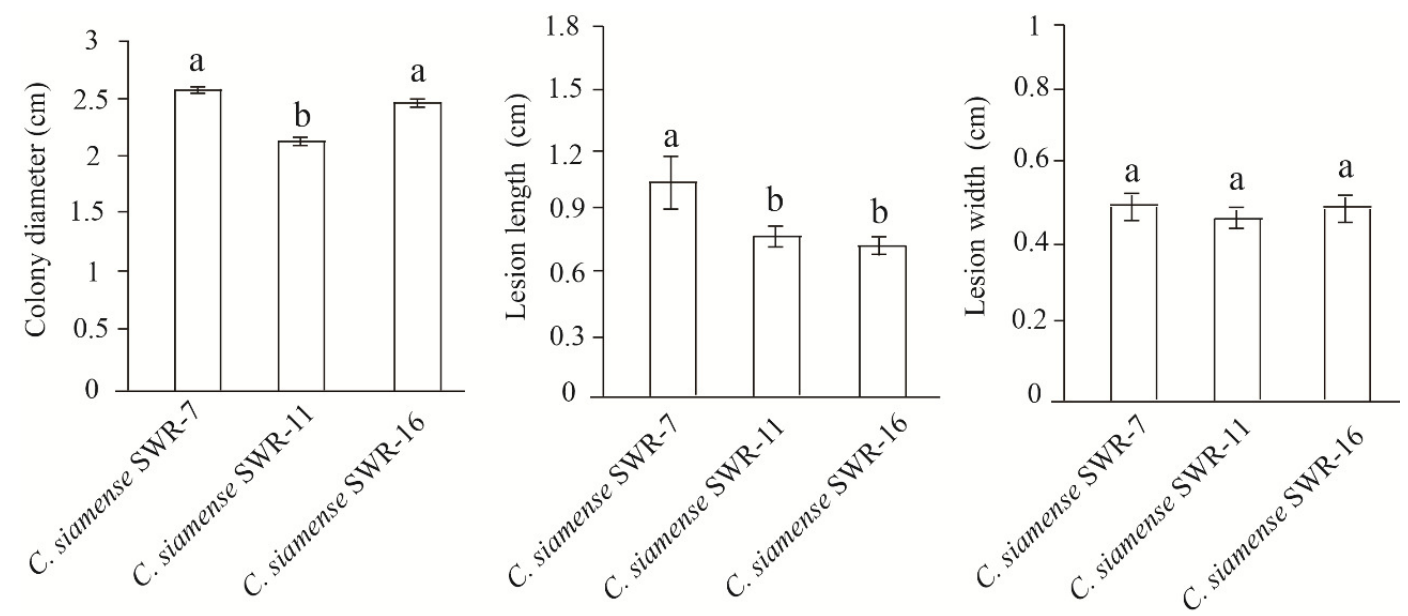

Figure 4. Mycelial growth indexes of different Colletotrichum siamense isolates

Colony diameter of different $C$. siamense isolates on PDA; Lesion length and lesion width of different $C$. siamense isolates on strawberry crown. Data (Means $\pm S E, n=6$ ) followed by different letters above the bars among treatments indicate significant differences at the $5 \%$ level.
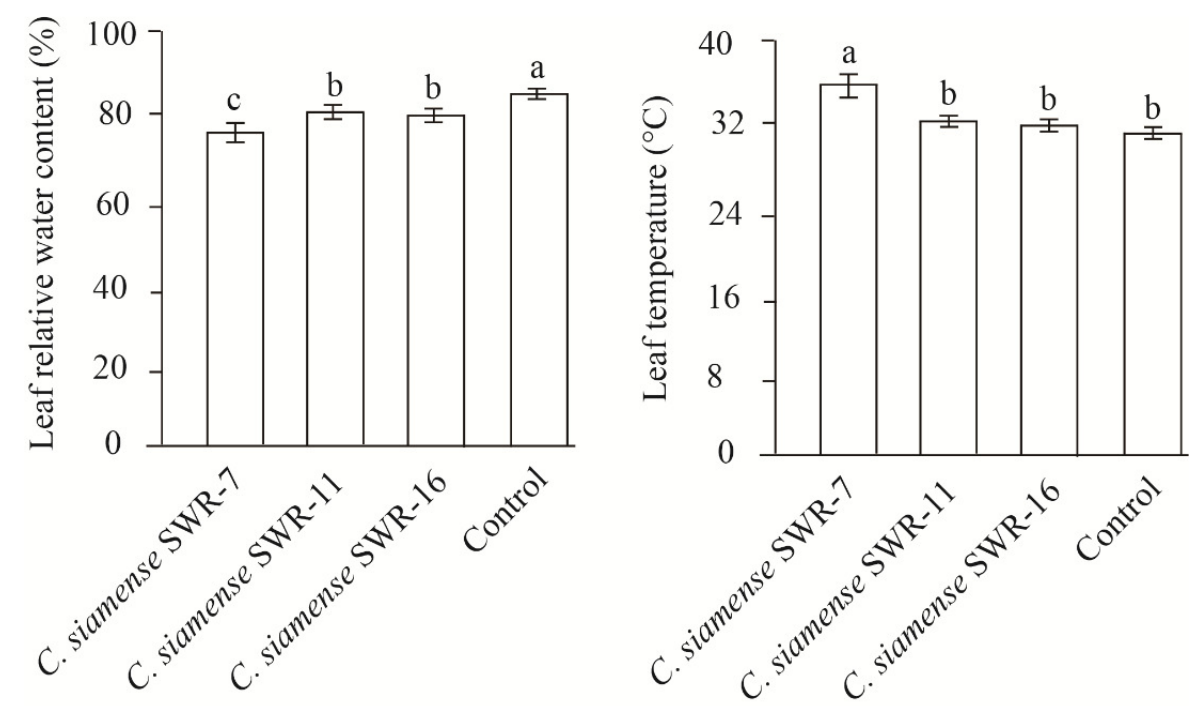

Figure 5. Effects of different Colletotrichum siamense isolates on relative water content and temperature of strawberry leaf

Data (Means \pm SE, $\mathrm{n}=6$ ) followed by different letters above the bars among treatments indicate significant differences at the $5 \%$ level. 

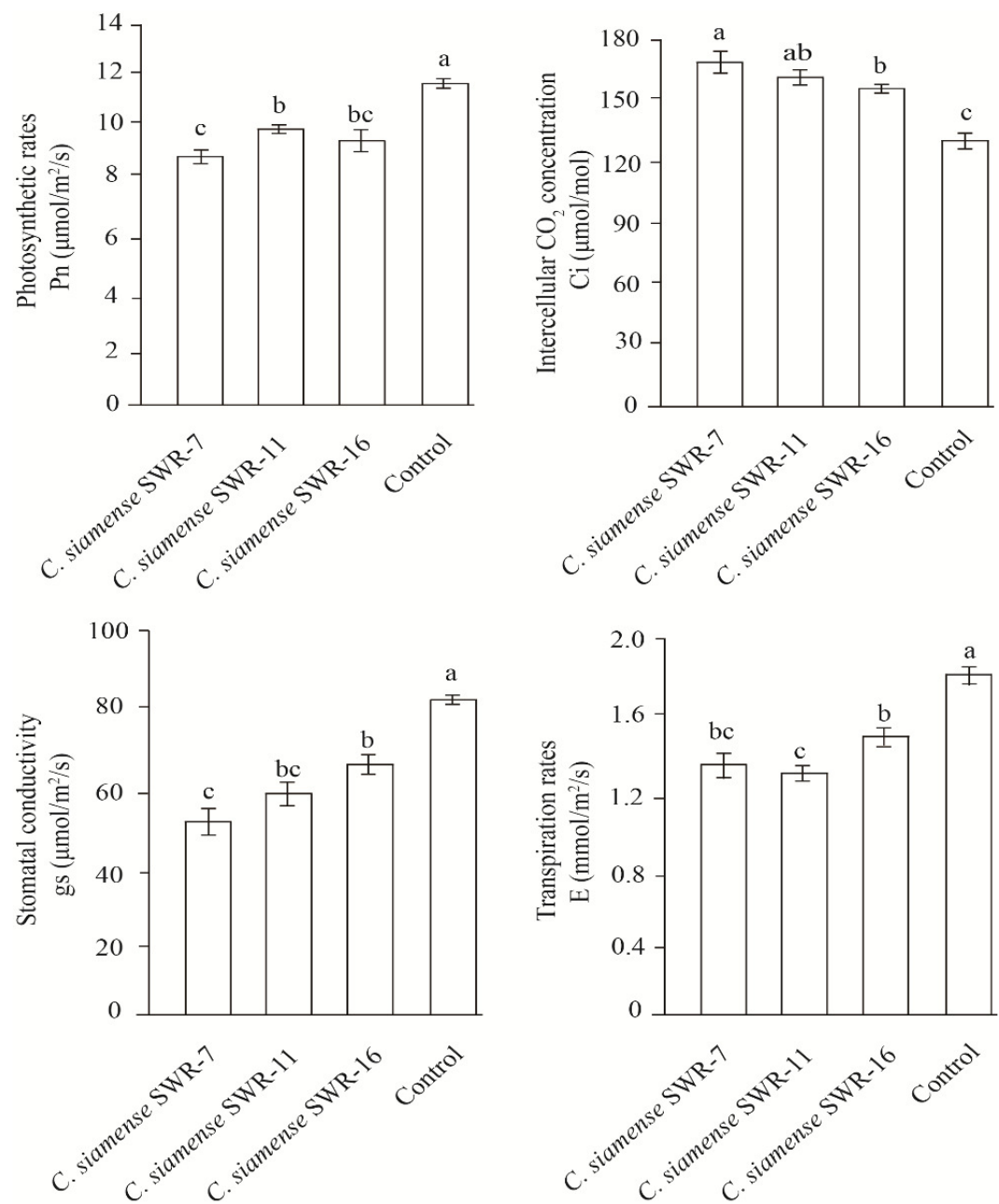

Figure 6. Effects of different Colletotrichum siamense isolates on strawberry leaf photosynthetic parameters including photosynthetic rates $(\mathrm{Pn})$, stomatal conductivity (gs), transpiration rates (E), leaf temperature, and intercellular $\mathrm{CO}_{2}$ concentration $(\mathrm{Ci})$

Data (Means $\pm S E, n=6$ ) followed by different letters above the bars among treatments indicate significant differences at the $5 \%$ level.

\section{Discussion}

Pathogens causing strawberry root and crown rot included Colletotrichum, Phytophthora, Neopestalotiopsis and Macrophomina (Noh et al., 2018; Park et al., 2019; Zhang et al., 2020; Chung et al., 2020). The pathogen of Colletotrichum sp. was worldwide and cause crown rot heavily (He et al., 2019). Earlier studies have shown that there were three pathogens of strawberry anthracnose, namely, $C$. gloeosporioides, $C$. acutatum and C. fragariae (Peres et al., 2005). Among them, C. gloeosporioides and C. fragariae mainly infected root crown, petiole and stolon of strawberry to cause root crown rot, which was collectively referred to as Anthracnose Crown Rot; $C$. acutatum mainly infected fruits to cause fruit anthracnose, and rarely infected root caps (Peres et al., 2005). Recently it was reported that $C$. gloeosporioides was the main pathogen of strawberry anthracnose (Jacobs et al., 2019), and C. gloeosporioides was a compound species including 22 species and 1 subspecies (Weir et al., 2012). Among them, C. gloeosporioides, C. fructicola, C. siamense, C. 
aenigma and C. changpingense were identified to causing crown rot (Han et al., 2016; Jayawardena et al., 2016; Adhikari et al., 2019). Our study showed twenty-one isolates were ensured as pathogen of strawberry crown rot by Koch's postulates (Figure 1). On PDA, twenty-one isolates showed three different types of colonies colour, which were grey colonies on the front and red wheel in back, white colonies with red rings on the front and yellow wheel in back, grey colonies on the front and black speck in back (Figure 2; Figure 3). The conidia morphology of three types of fungi with different colonial morphology was nearly the same. Thus the $C$. siamense was the pathogen of strawberry crown rot in Jingzhou Hubei province, same as the crown rot pathogen in Wuhan (Han et al., 2014). However, the three isolates of our study showed distant phylogenetic relationships with $C$. siamense strain Zhd-5, C. siamense strain Zhd-4-1 and C. siamense strain Zhd-3 identified in Wuhan. This suggested the $C$. siamense presented high diversity due to different region and environment.

C. siamense is capable of causing crown rot disease which is characterized by reddish brown rhizomes with less roots and wilted leaves. According to the comparation of lesion length, lesion width, indexes of leaf relative water content, and temperature and photosynthetic parameters, the pathogenicity of three type's $C$. siamense isolates was different. The isolates of $C$. siamense SCR-7 showed the strongest pathogenicity which caused the highest values of lesion length and leaf temperature (Figure 4), lowest leaf relative water content (Figure 5), and lowest Pn, gs even E value of the three isolates (Figure 6), which suggested not only lesion index but also relative water content and photosynthetic parameters could evaluate the pathogen pathogenicity (Tan et al., 2005; Yang et al., 2014; Calonnec et al., 2018; Xue et al., 2018). The isolates of C. siamense SCR-7 and SCR-16 exhibited the highest mycelial growth rate, but $C$. siamense SCR-16 showed lower pathogenicity than C. siamense SCR-7. This result suggested us there was an inevitable connection between mycelial growth rate on PDA flat and pathogenicity on plant tissue, which might contribute to the growth process of the isolates was different between PDA flat and strawberry crown as previous study stated (Irzykowska et al., 2008; Irani et al., 2011; Wang et al., 2011; Lu et al., 2018). In addition, the different pathogenicity of three isolates suggested us further clarifications of $C$. siamense and systemic pathogenicity analysis are needed.

\section{Conclusions}

The objective of this study was to identify the pathogen causing crown rot on strawberry in Jingzhou, China, and to provide a basis for disease prevention and resistance breeding. Twenty-one isolates were characteristic as pathogen of crown rot of strawberry by Koch's postulates, and all of them were identified as Colletotrichum spp. Based on conidia morphology observation. Twenty-one isolates were divided into three groups based on colony morphology, and isolates SCR-7, SCR-11 and SCR-16 were belonged to each group, respectively. Three isolates SCR-7, SCR-11 and SCR-16 were characterized as $C$. siamense by actin, $\beta$ Tubulin 2 and calmodulin gene sequences. In addition, the pathogenicity of three types of $C$. siamense isolates was different. The isolates of $C$. siamense SCR-7 showed the strongest pathogenicity which caused the highest values of lesion length and leaf temperature, and the lowest leaf water content, Pn, gs even E value of the three isolates. The results of biological characteristics and multigene loci analysis based on the sequences of TUB2, $A C T$, and $C A L$ concluded that the crown rot disease of strawberry occurred in Jingzhou was caused by $C$. siamense.

\section{Authors' Contributions}

BS conceived and designed the experiments, supervised and revised the manuscript. CL conducted part of the experiments and wrote the original manuscript. YH conducted part of the experiments. All authors read and approved the final manuscript 


\section{Acknowledgements}

This work was supported by the Scientific Research Foundation for Doctor of Yangtze University, grant number 802100270303 .

\section{Conflict of Interests}

The authors declare that there are no conflicts of interest related to this article.

\section{References}

Adhikari TB, Chacon JG, Fernandez GE, Louws FJ (2019). First report of anthracnose causing both crown and fruit rot of strawberry by Colletotrichum siamense in North Carolina. Plant Disease 103(7):1775-1775. https://doi.org/10.1094/PDIS-02-19-0314-PDN

Calonnec A, Jolivet J, Vivin P, Schnee S (2018). Pathogenicity traits correlate with the susceptible Vitis vinifera leaf physiology transition in the biotroph fungus Erysiphe necator: an adaptation to plant ontogenic resistance. Frontiers in Plant Science 9:1808. https://doi.org/10.3389/fpls.2018.01808

Chung PC, Wu HY, Wang YW, Ariyawansa HA, Hu HP, Hung TH, ... Chung CL (2020). Diversity and pathogenicity of Colletotrichum species causing strawberry anthracnose in Taiwan and description of a new species, Colletotrichum miaoliense sp. nov. Scientific Reports 10:14664. https://doi.org/10.1038/s41598-020-70878-2

Damm U, Cannon PF, Woudenberg JHC, Johnston PR, Weir BS, Tan YP, ... Crous PW (2012). The Colletotrichum boninense species complex. Studies in Mycology 73:1-36. https://doi.org/10.3114/sim0002

Gunnell PS, Gubler WD (1992). Taxonomy and morphology of Colletotrichum species pathogenic to strawberry. Mycologia 84(2):157-165. https://doi.org/10.1080/00275514.1992.12026122

Han YC, Zeng XG, Xiang FY, Ren L, Chen FY, Gu YC (2016). Distribution and characteristics of Colletotrichum spp. associated with anthracnose of strawberry in Hubei, China. Plant Disease 100(5):996-1006. https://doi.org/10.1094/PDIS-09-15-1016-RE

Han YC, Xiang FY, Zeng XG, Zhang P, Gu YC (2014). Identification of pathogen causing crown and root rot on strawberry. Scientia Agricultura Sinica 47(1):53-60. https://doi.org/10.3864/j.issn.0578-1752.2014.01.006

He C, Duan K, Zhang L, Zhang L, Song L, Yang J, ... Gao Q (2019). Fast quenching the burst of host salicylic acid is common in early strawberry/Colletotrichum fructicola interaction. Phytopathology 109(4):531-541. https://doi.org/10.1094/PHYTO-02-18-0043-R

Huang GM, Zou YN, Wu QS, Xu YJ, Kuča K (2020). Mycorrhizal roles in plant growth, gas exchange, root morphology, and nutrient uptake of walnuts. Plant, Soil and Environment 66(6):295-302. https://doi.org/10.17221/240/2020-PSE

Irani H, Heydari A, Javan-Nikkhah M, İbrahimov A (2011). Pathogenicity variation and mycelial compatibility groups in Sclerotinia sclerotiorum. Journal of Plant Protection Research 51(4):329-336 https://doi.org/10.2478/v10045-011-0054-4

Irzykowska L, Bocianowski J (2008). Genetic variation, pathogenicity and mycelial growth rate differentiation between Gaeumannomyces graminis var. tritici isolates derived from winter and spring wheat. Annals of Applied Biology 152(3):369-375. https://doi.org/10.1111/j.1744-7348.2008.00226.x

Jacobs RL, Adhikari TB, Pattison J, Yencho GC, Fernandez GE, Louws FJ (2019). Inheritance of resistance to Colletotrichum gloeosporioides and C. acutatum in strawberry. Phytopathology 109(3):428-435. https://doi.org/10.1094/phyto-08-18-0283-r

Jayawardena RS, Huang JK, Jin BC, Yan JY, Li XH, Hyde KD, ... Zhang GZ (2016). An account of Colletotrichum species associated with strawberry anthracnose in China based on morphology and molecular data. Mycosphere 7(8):1147-1191. https://doi.org/10.5943/mycosphere/si/2c/6 
Liu F, Damm U, Cai L, Crous PW (2013). Species of the Colletotrichum gloeosporioides complex associated with anthracnose diseases of Proteaceae. Fungal Diversity 61(1):89-105. https://doi.org/10.1007/s13225-013-0249-2

Lu X, He S, Ma H, Li J, Zhu F (2018). Hormetic effects of flusilazole preconditioning on mycelial growth and virulence of Sclerotinia sclerotiorum. Plant Disease 102(6):1165-1170. https://doi.org/10.1094/pdis-10-17-1638-re

Noh YH, Oh Y, Mangandi J, Verma S, Zurn JD, Lu YT, ... Lee S (2018). High-throughput marker assays for FaRPc2mediated resistance to Phytophthora crown rot in octoploid strawberry. Molecular Breeding 38(8):1-11. https://doi.org/10.1007/s11032-018-0861-7

Park K, Han I, Lee SM, Choi SL, Kim MC, Lee H (2019). Crown and root rot of strawberry caused by Neopestalotiopsis clavispora in Korea. The Korean Journal of Mycology 47(4):427-435. https://doi.org/10.4489/KJM.20190047

Peres NAR, Timmer LW, Adaskaveg JE, Correll JC (2005). Lifestyle of Colletotrichum acutatum. Plant Disease 89(8):784-796. https://doi.org/10.1094/PD-89-0784

Tamura K, Dudley J, Nei M, Kumar S (2007). MEGA4: molecular evolutionary genetics analysis (MEGA) software version 4.0. Molecular Biology and Evolution 24(8):1596-1599. https: / doi.org $/ 10.1093 / \mathrm{molbev} / \mathrm{msm092}$

Tan JJ, Ye JR, Wu XQ, Zhu YF, Li Y (2005). A study on disease development and early diagnosis of pine wood nematode, Bursaphelenchus xylophilus, infection of Japanese black pine. Nematology 7(4):481-485. https://doi.org/10.1163/156854105774384787

Wang F, Zhao L, Li G, Huang J, Hsiang T (2011). Identification and characterization of Botryosphaeria spp. causing gummosis of peach trees in Hubei Province, central China. Plant Disease 95(11):1378-1384. https://doi.org/10.1094/PDIS-12-10-0893

Weir BS, Johnston PR, Damm U (2012). The Colletotrichum gloeosporioides species complex. Studies in Mycology 73:115-180. https://doi.org/10.3114/sim0011

Xie L, Zhang JZ, Wan Y, Hu DW (2010). Identification of Colletotrichum spp. isolated from strawberry in Zhejiang Province and Shanghai City, China. Journal of Zhejiang University Science B 11(1):61-70. https://doi.org/10.1631/jzus.B0900174

Xue C, Liu Z, Dai L, Bu J, Liu M, Zhao Z, ... Zhao J (2018). Changing host photosynthetic, carbohydrate, and energy metabolisms play important roles in Phytoplasma infection. Phytopathology 108(9):1067-1077. https://doi.org/10.1094/PHYTO-02-18-0058-R

Yang C, Zhang Z, Gao H, Liu M, Fan X (2014). Mechanisms by which the infection of Sclerotinia sclerotiorum (Lib.) de Bary affects the photosynthetic performance in tobacco leaves. BMC Plant Biology 14:240. https://doi.org/10.1186/s12870-014-0240-4

Zhang LQ, Song LL, Xu XM, Zou XH, Duan K, Gao QH (2020). Characterization and fungicide sensitivity of Colletotrichum species causing strawberry anthracnose in eastern China. Plant Disease 104(7):1960-1968. https://doi.org/10.1094/PDIS-10-19-2241-RE

Zou YN, Srivastava AK, Ni QD, Wu QS (2015). Disruption of mycorrhizal extraradical mycelium and changes in leaf water status and soil aggregate stability in root box-grown trifoliate orange. Frontiers in Microbiology 6:203. https://doi.org/10.3389/fmicb.2015.00203
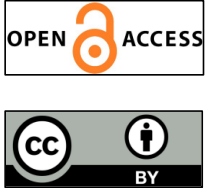

The journal offers free, immediate, and unrestricted access to peer-reviewed research and scholarly work. Users are allowed to read, download, copy, distribute, print, search, or link to the full texts of the articles, or use them for any other lawful purpose, without asking prior permission from the publisher or the author.

License - Articles published in Notulae Botanicae Horti Agrobotanici Cluj-Napoca are Open-Access, distributed under the terms and conditions of the Creative Commons Attribution (CC BY 4.0) License. (C) Articles by the authors; UASVM, Cluj-Napoca, Romania. The journal allows the author(s) to hold the copyright/to retain publishing rights without restriction. 